\title{
Reflets
}

Revue ontaroise d'intervention sociale et communautaire

\section{La réalité du Nord}

\section{Monique Rocheleau}

Volume 2, numéro 1, printemps 1996

Contrer la violence subie par les femmes et les enfants en milieu familial

URI : https://id.erudit.org/iderudit/026120ar

DOI : https://doi.org/10.7202/026120ar

Aller au sommaire du numéro

Éditeur(s)

Reflets : Revue ontaroise d'intervention sociale et communautaire

ISSN

1203-4576 (imprimé)

1712-8498 (numérique)

Découvrir la revue

Citer cet article

Rocheleau, M. (1996). La réalité du Nord. Reflets, 2(1), 188-191.

https://doi.org/10.7202/026120ar

Tous droits réservés (C) Reflets : Revue ontaroise d'intervention sociale et communautaire, 1996

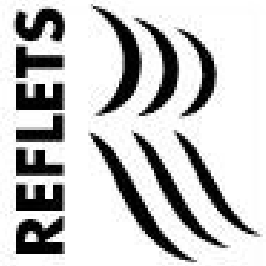

Ce document est protégé par la loi sur le droit d'auteur. L’utilisation des services d'Érudit (y compris la reproduction) est assujettie à sa politique d'utilisation que vous pouvez consulter en ligne.

https://apropos.erudit.org/fr/usagers/politique-dutilisation/ 


\section{La réalité du Nord}

\section{M onique R ocheleau}

Intervenante, $\mathrm{C}$ entre de $\mathrm{C}$ ounselling familial, $\mathrm{T}$ immins

Les compressions budgétaires imposées par le gouvernement $\mathrm{H}$ arris sont causes de grandes inquiétudes dans les services de santé et aux services sociaux. Ces restrictions nous portent à croire que les femmes et les enfants en seront victimes. En effet, les coupures faites aux prestations familiales, de bien-être social, aux services offerts par les maisons d'hébergement, aux programmes contre la violence ou aux services de garde pour enfants, rendent de plus en plus difficile la lutte contre les inégal ités sociales, tout particulièrement dans le domaine de la violence faite aux femmes. $C$ 'est ce dernier point que je vais aborder.

L'histoire de la civilisation permet de constater les inégalités entre hommes et femmes. $\mathrm{O} r$, le gouvernement $\mathrm{H}$ arris semble animé par une volonté de remettre, une fois de plus, les femmes et leurs enfants dans une position de subordination, et une situation de détresse matérielle. $E n$ cherchant à réduire le déficit, le gouvernement actuel touche directement les femmeset lesenfants. La majorité des femmes est déjà dans une position économique désavantagée. Pour survivre, nombreuses sont celles qui doivent faire appel aux programmes sociaux afin de subvenir à leurs besoins et à ceux de leurs enfants. $D$ ans ce contexte, les femmes et les enfants deviennent les boucs émissaires d'une société qui cherche à imposer des restrictions au bien-être de nos familles, dans le but de réduire la dette publique.

Selon une étude faite par Statistique C anada, en 1991, 50 \% de la dette est attribuée au fait que les riches et les corporations évitent de payer les impôts, $44 \%$ aux taux d'intérêt, 2 \% aux programmes sociaux, et $4 \%$ à d'autres facteurs. Pourquoi alo rs cibler 
les personnes les plus vulnérables de notre société, et pourquoi viser les programmes sociaux destinésà venir en aide aux femmes et aux enfants?

$\mathrm{D}$ ans le $\mathrm{N}$ ord, ces nombreuses compressions auront des conséquences graves car les femmes et leurs enfants n'auront plus accès, ou un accès limité, à des services qui leur étaient autrefois offerts. En effet, lorsd'une récente tournée du C onseil consultatif de l'O ntario sur la condition féminine (1995), dans les diverses régions du $\mathrm{N}$ ord, les femmes ont souligné les lacunes suivantes: manque de logements à prix modique, manque de services médicaux et sociaux de qualité, besoin de services de garde abordables et accessibles, etc. Ces demandes soulignent que les femmes ont des possibilités économiques limitées, particulièrement les femmes francophones, autochtones et de milieux ruraux, de minorités visibles et immigrantes. $0 \mathrm{n}$ pouvait déjà dire que les services destinés aux femmes et aux enfants du N ord de I'O ntario étaient précaires. $M$ aintenant, certains services n'existent plus. C'est le cas entre autres, des services pour les enfants témoins ou victimes de la violence, ou des programmes de réadaptation pour hommes violents. $M$ algré le discours du gouvernement $\mathrm{H}$ arris sur l'importance des enfants, il néglige les services qui tentent de leur assurer la protection, leur croissance et une vie familiale saine.

Le système judiciaire répond de façon inadéquate aux accusations de mauvais traitements physiques et d'agressions sexuelles contre les femmes et les enfants. Si l'homme est trouvé coupable, la peine est souvent peu sévère. Par ailleurs, comme l'indique le rapport de la tournée du Conseil consultatif sur la condition féminine de l'O ntario, les programmes de traitement pour hommes violents sont souvent difficiles à imposer. Si I'homme ne participe pas volontairement au programme, conformément à l'ordonnance du tribunal, et que son agent de probation dénonce ce manquement à la loi, rien ne sera fait pour le contraindre. $0 \mathrm{n}$ abandonnera tout simplement les démarches. De plus, la police néglige souvent de faire respecter les ordonnances restrictives ou l'obligation de ne pas troubler la paix publique, mesures destinées à tenir éloignés de la famille les conjoints violents. 
L'importance que revêt l'intervention du système de justice pénale dans les cas de violence conjugale repose, d'une part sur la notion qu'il convient de punir sévèrement les hommes qui commettent des voies de fait contre leur partenaire, et d'autre part sur l'espoir que le système de justice pénale peut aider les hommes violents à modifier leur comportement. Les nombreuses compressionsimposées par le gouvernement semblent de plus en plus en diminuer l'importance. $D$ ans tout ce processus, la femme se voit privée de presque tous ses droits, et dévalorisée en tant que personne. Sa vie et celle de ses enfants sont en danger, et la société n'est pas en mesure de la protéger convenablement.

Selon les recherches de D obash et D obash (1979) et Walker (1979), il faut porter une attention spéciale aux enfants qui ont été victimes ou témoins de la violence. La décision de la mère de quitter un foyer violent repose souvent sur le fait qu'elle désire protéger ses enfants. Les enfants deviennent alors des catalyseurs dans le processus décisionnel de la femme de chercher de l'aide. D ès lors, le processus de réadaptation de l'enfant doit combler les difficultés affectives et physiquesqu'on voit chez la majoritéd'entre eux ayant vécu des incidents de violence ou en ayant été témoins. O $r$, les coupures dans ces services font que les femmes ou les enfants ne peuvent plus avoir accès à un système de protection sociale et judiciaire. Les enfants sont une ressource importante de notre société. C'est à travers eux qu'il faut intervenir pour modifier un système de valeurs, de normes sociales qui ont perpétué la violence.

Le gouvernement $\mathrm{H}$ arris, par ses multiples coupures budgétaires, tend à suggérer que les femmes sont des personnes que les hommes peuvent légitimement dominer. D 'ailleurs, ce message est clairement perceptible dans le document intitulé «R évolution du bon sens\%. II encourage les valeurs d'une société bâtie sur la dévaluation des attributs et de l'apport des femmes, d'une société où la femme est considérée inférieure à l'homme, et où les valeurs et les attitudes sociales sanctionnent et encouragent les efforts masculins dans leur quête de pouvoir, et d'autorité. 


\section{Bibliographie}

CONSEIL CONSULTATIF DE L'ONTARIO SUR LA CONDITION FÉMININE (1995). Rapport de la tournée du $\mathrm{N}$ ord-est, Toronto, Conseil consultatif de l'O ntario sur la condition féminine.

D O BASH , R .E. et R . D O BASH (1979). V iolenceA gainstW ives: A C ase A gainst the Patriarchy, N ewYork, Free Press.

GO U VER N EM EN T DE L'O N TAR IO (1991). D onnées du recensement de 1991 deStatistiques C anada, Toronto, $M$ inistère des affaires civiques.

RO CHELEAU, M onique (1995). É valuation d'un programme de traitement pour hommes violents au C entre de counselling familial deT immins Inc, Thèse de maîtrise, U niversité Laurentienne, École de service social. 